\title{
A Review of Three Major Sociological Theories and an Islamic Perspective
}

\author{
HAYATULLAH LALUDDIN1
}

\begin{abstract}
This article examines critically the three major sociological theories namely, Structural Functionalism, Symbolic Interactionism and Conflict theory. These theories are formulated on the pattern of science where scientific method is strictly adhered to. Considering the nature and the essence of the social phenomenon and its component parts the author argues that the application of pure scientific method in the study or analysis of the social phenomenon fail to present an accurate understanding of the social phenomenon. Thus, an alternative method which is capable of taking into consideration both physical and metaphysical aspects of the social phenomenon is required. Toward this end this article attempts to delineate the three major theories of sociology, their shortcoming and loophole, then attempt to highlight the constituent elements of the social phenomenon and their significance in formulation of comprehensive sociological theories. An Islamic perspective on sociological theories is also provided in the last part of this article where the discrepancy of the sociological theories are disclosed and a proposal for a more dynamic method for the formulation of sociological theories of comprehensive nature is made.
\end{abstract}

Keywords: functionalism, interactionism, Islam and social phenomenon, social conflict, sociological theory

Social theory to a great extent is older than sociology itself. It can be found in the Old Testament, Hindu's Vedas and Chinese literature. Even social theories of modern social science orientation can be traced back 2400 years to ancient Athens. They were used as a means of visualising the social universe in order to obtain practical knowledge about it. (Caplow 1971: 156). However, modern sociology, as a science of society, emerged only after the extension of scientific method into the social world. This happened in early nineteenth century when systematic efforts were made to evolve a science of society as a distinct perspective from philosophy, history, politics, economy and other social sciences. (Cotgrove 1967:32). However, efforts at establishing a separate identity for the science of society involved formulation of various theories about the nature of social system and the methods of their study. Sociologists in pursue of this, formulated different theories from which three are the most popular. Therefore, this paper deals with the three major sociological theories namely, Structure Functionalism, Symbolic Interactionism and Conflict Theory.

${ }^{1}$ HAYATULLAH LALUDDIN, Ph.D., assistant professor at the Department of Economics, Kulliyyah of Economics and Management Sciences, International Islamic University Malaysia, Jalan Gombak, 53100 KUALA LUMPUR, Malaysia, email: hayatul@iium.edu.my.

https://doi.org/10.24035/ijit.10.2016.002 


\section{Structural Functionalism}

Charon (1992) views Structural Functionalism as a sociological theory that depicts society as a social system consisting of various structures, organizations and institutions, influencing each other and affecting the whole system. It focuses on the function of the institutions and their contribution to the continuity of the social system.Although some historians trace functionalism to Montestquieu (Cohen 1968:34 ) its roots can be traced to works of Herbert Spencer (1820-1903) an English sociologist, Wilfredo Pareto, (18481923) an Italian sociologist and Emile Durkheim (1855-1917) French sociologist (Joel 1991). Furthermore, some insights to functionalism can be drawn from August Comte's (1798-1857) concept of social static, a study of the coexistence of social phenomenon, based on the assumption of the interrelatedness of institutions, belief and morals of the society. He proposed this as one part of sociological inquiry in which the existence of each item in the whole is explained by the law that prescribe its manner of coexistence with other (Cohen 1968).

Herbert Spencer suggested a structural analysis of society by drawing functional analogy between society and an organism. According to him, society like organism displays different levels of structural complexity, which can be measured in terms of different component elements of its structures. Thus, a structure composed of identical elements would more or less be self-sufficient. But composition of the structure from unlike elements needs a greater degree of interdependence. Therefore, the degree of the integration of the whole depends on the extent of the difference that exists between the individual structural elements. In other words, the existence of more difference between the structural elements brings about greater integration in the whole and enables it to survive by reducing its internal disharmony. Thus, Spencer contributed something new to functionalism by analysing the different levels of complexity of society in terms of structural component and their contribution to functioning of the whole.Structural Functionalism, as Percy observed, is more indebted to Emile Durkheim than Spencer. Even though, like Spencer, he was influenced by biological thinking in his early stage of writings, yet he was able to identify some of the loopholes in its explanation (Cohen 1968: 35-36). By doing so he made the theory more attractive and useful to social anthropologists as well as sociologists in general.

Durkheim analysed division of labour, in terms of its cause and function hence, holding integration or reintegration of society as its function and moral density as its cause. He attributed the breakdown of the constraints built into simple society to pressure caused by growth of population and the broad scope of interaction. This led to an intensified competition which if left uncontrolled could destroy the society. To control this, Durkheim, suggested division of labour as a potential means of creating interdependency between the individual members of society supported further by acceptance of morality of mutual obligation (Durkhiem1984: 35). Thus, Durkhiem's analysis of division of labour, in terms of moral density as its cause and integration or reintegration of society as its function by creating interdependency between its individual members, is an important step in the direction of functional analysis of social phenomenon, hence, significant source of derivation of the theory of Structure Functionalism.

Durkheim also rejected explanation of religion in terms of intellectual and emotional characteristics of individuals. He viewed religion as a social phenomenon explainable in terms of the collective need of individuals by which solidarity and an awareness of the social derivation of the moral order of society is expressed. He viewed society as an external 
force constraining individuals by providing them with necessary moral rules and norms and cultural resources in the light of which they can lead their life (Durkhiem 1984: 37). Emile Durkheim analysis of religion as a moral order derived from society with the symbolic function of expressing solidarity among its members and their awareness of its social derivation, can be considered another important step towards formulation of Structure Functionalism as a sociological theory.

Basically, Structural Functionalism views society as a social order and attempts to find how it is achieved and perpetuate in society. It also focuses on how different parts of social system by performing their specific function, contribute to the whole structure. In this sense, it presents an optimistic picture of society where every component of the social structure is perceived to be contributing to the functioning of the whole. For example, family as a subpart of the whole structure socializes children and control sex, religion enhances integration in society by bringing its individual members together. Schools educate people and train them for different positions in the society, while police control people by preventing them from threatening social order. These all are positive functions performed by different parts of the social system hence, contributing to maintaining order in the whole. Thus, the survival of the society as a complex working whole depends on its parts whose overall contribution lead to its functioning.

Besides, viewing society as social order, it also sees society as a consensus among the individuals on a body of rules and law, which are based on custom, moral and values of the society and reinforces the work of its interdependent parts. In this manner it contributes to the continuation of the social system. However, consensus is not a given phenomenon in society. For, it is achieved through the process of socialization where individuals came to agree to the rules and law of a society. Other institutions such as religion, schools, police and press etcetera also support socialization further by encouraging individuals to be part of this consensus. Thus, society through socializing its members instils a strong sense of commitment to its rules and law and form consensus among them. By doing so the society is able to exert influence on individuals and secures its own continuation (Charon 1992:140-44).

\section{Its Formation as a Sociological Theory}

Although the roots of Structural Functionalism can be traced to the works of writers mentioned above, its emergence as a full-fledged sociological theory of modern implication, can be attributed to Bronislaw Malinowski (1884-1942) and A. R. Radcliffe Brown (18811955) and others. Malinowski after carrying out ethnographic research amongst the Australian aborigines found that it was not guiding his research, for they were more in the nature of elaboration of assumptions that he worked out during his research. This led him to the first formulation of functionalism, which he considered useful in the understanding of any particular cultural item. The basic ideas that led to formulation of functionalism were based on the assumptions that there is a general principle to human conduct by which it can be explained, and that each cultural items has some other contextual elements for its occurrence. Thus, in understanding of a particular cultural item of a society, it is necessary to refer to these general principles of human conduct and contextual items of its occurrence (Malinowski 1962: 132-33). For example, in Trobriand tribe male makes payment to his sister's husband. In explaining this practice, one refers first to certain general principles of 
reciprocity, which govern conduct in all societies and secondly, to the fact that it is a matrilineal society where man is succeeded by his sister's son.

Obviously, this kind of analysis explains Trobrianders practice of payment to sister's husband in terms of present structure of the society namely, matrilineal system where lineage follow female side, and not in terms of its being evolved from patriarchal system of the past, an assumption of speculative nature. It also does not agree with interpretation of this practice as an evidence of patriarchal survivals. Thus, in this example the particular item of Trobriand tribe is explained in terms of the general principle of reciprocity and the function of matrilineal structure of the tribe in the present. This is an approach to the study of social phenomenon that lay at the very essence of the Theory of Structural Functionalism.

Subsequently, Malinowski formulated a theory of functional analysis based on some biological and psychological presumptions. He assumed that humanshave some primary needs such as, food, shelter, sexual satisfaction, protection and so on. To meet these needs, they devised techniques for growing or finding and distributing food, construction of dwelling and the establishment of heterosexual relation. Beside primary needs there exist secondary needs such as need for communication and language. The need for control of conflict and enhancement of cooperation give rise to social norms and social sanctions. Man's awareness of danger of life led to some forms of rituals and religion to alleviate the anxieties caused by uncertainty. The satisfaction of secondary needs necessitated formulation of elaborate coordinative institutions followed by the need for rules of succession and some mechanism of legitimating authority(Malinowski 1962: 132-33).From his analysis of primary and secondary needs in the context of the means of their realization, it became clear that every cultural item of the social life has a function of fulfilling some present needs, an affirmation that led to the establishment of Structure Functionalism as a sociological theory.

Percy identified Radcliffe Brown as another sociologist who takes some important steps in the direction of establishing Structure Functionalism as a sociological theory. Although he was not willing to be called a functionalist, he formulated a theory similar to that of Malinowski. Like Durkheim, he favoured explaining cultural and social phenomena in social terms in the present. He based his explanation of social phenomenon on four basic assumptions.:

1. Society's survival depends on some minimal level of solidarity among its members.

2. There exists at least minimal level of consistency in relation between the parts of social system.

3. Society consists of some basic structures and practices that are related to each other. This relationship can be shown in a way that contributes to their maintenance as a whole.

4. Social structure and its requirements cannot be reduced. This indicates his tendency of explaining other things such as ideas, and ritual practices in terms of social structures(Cohen1968: 38-38).

Although the credit of explicit formulation of Structure Functionalism goes to Malinowski and Radcliffe, this by no means implies their exclusive right to the formation of the theory. There are others who also made some contributions to enriching the theory and refining it, which is discussed briefly in the following. 
Talcott Parsons(1902-1979), an American sociologist, made new significant contributions to structural functionalism. He viewed society as a system of fundamentally interrelated variables, which can be analysed in terms of their function and as part of a boundary-maintaining system (Parsons 1949). Combining some of Malinowski's ideas with that of Pareto and Durkheim, Parsons treated the needs of personality as variables in a social system. He also analysed professional rule as a variable of a social system in terms of its function, which he held to be the definition of the conditions of entry and rights, and obligations of professional practitioner. It also demarcates the boundary of the profession and facilitates interpersonal relation between professional practitioner and his client (Cohen 1968: 42-43).

Certainly, formulation of a theory of functional analysis for every system is not Parsons only concern for, he also elaborates on the functional prerequisites of every social system. He depict functional prerequisites of the system and the personality of its members as an absolute operational requirement of the system. Physical needs for survival catered for by allocation of material sources represents the prerequisites of the personality of the members. Beside physical needs of the members of the society there are some non-material needs exemplified by conformity and compliance to the norms of the society. The necessity for this requirement is clear from the fact that an individual not upholding or not respecting the norms of the society will be rejected by other members of the society. Thus, in this sense conformity to the norms of the society can be considered as the non-material needs of the members of the society. This need is catered for through socialization by means of participation in some activities organized by society (Cohen 1968: 45). It is therefore, necessary for every social system to have specific norms and some fundamental values by means of which the members internalise a sense of conformity and compliance to the social norms.

However the system related prerequisites, as Percy noted, consist of the organization of some activities by the system and establishment of institutions for checking its efficiency hence, dealing with it appropriately. Thus, in order for a system to operate successfully a certain level of compatibility between all its structures is necessary. The driving force behind Parson elaborate discussion of the functional prerequisites of each social system and their comparison, seems to be his assumption that it will facilitate a precise explanation of the operation of a social system. He chose this approach as an alternative to sets of equations describing social system in terms of fundamental relations in a mathematical sense (Parsons 1949: 224). From the forgoing discussion it becomes clear that Parsons favoured expressing the equilibrium of social system in statements of mathematical accuracy. A wishful thought which is yet to be realised.

Parsons viewed society as a system of functionally related structure, where functions are distributed among its major parts. For example, economics as a major part of social structure is tasked with the provision of good and services crucial for its survival, polity with the function of mobilizing the resources and their allocation to a hierarchy of goals, in terms of strict compliance with the principle of priority, kinship or cultural structure, with the function of moral integration in the society (Cotgrove1967: 34). However, the distribution of the function among the major structures of the system, does not guarantee functionality of all the elements in a society. For, some practices constituting part of a social structure may be survival of the past with no significant role in the present. Stephen illustrates this by citing an example of the button on the sleeves of man's jacket, which may function as a sign of differentiating tailor-made jacket from mass-produced suits, 
a function of no significant importance. Furthermore, some practices may be functional for some societies and dysfunctional for other. For example, trade unions and employers association may function as a means of protecting their interest. At the same time it may have a negative impact on the interest of other groups. In the case of former it is functional, while in later case it is dysfunctional.

Admittedly, Parsons' most important contribution to Structural Functionalism was his identification of the four basic problems of social system, consisting of goal attainment, adaptation, integration and latency or pattern maintenance and tension management (Caplow1971: 185). Goal attainment being the aim of all social action, involves the problems of adaptation of appropriate means to the ends and the allocation of resources for different goals. Adaptation includes coming into terms with the external situation and environment of a social system, and also devising appropriate techniques for attainment of its intended gaols. Integration is concerned with safeguarding order in the social system by maintaining internal relations between its different units. For example, in a factory integration is achieved by maintaining good relation between managers and workers. Latency or pattern maintenance deals with the problem of maintaining adequate motivation among the constituent elements of the system and with that of resolving the tension, which may crops up during the interaction between the units and the system (Cotgrove 1967: 33).

Every social system faces internal and external situations and supports two kinds of activities. Each of these activities is either of instrumental nature or expressive function. For example, goal attainment and adaptation play instrumental function by dealing with the allocation of means to achieve ends. On the other hand, integration and latency are expressive functions, maintaining an appropriate emotional state of the units for the performance of instrumental tasks (Cotgrove 1967: 34). Parsons' view of society as a system of functionally related parts formulated a systematic theory of functional analysis with the potential of generating new insights into the understanding of social phenomenon. This highly underscores the merit of his theory of Structure Functionalism, for it provides a framework for empirical research.

Robert K. Merton, refined the theory of Structure Functionalism with a great deal of care, thus avoiding other functionalists fallacies, such as viewing what is good for system is necessarily good for individual or the view that a system with equilibrium is worthy of preservation. Similarly, he avoided the false notion of seeing conformity more valuable than that of nonconformity. This was due to his ability in seeing the function of the constituent element of social system from a broader perspective. According to him, every component element of the social system, beside manifest function, has latent function which is unintended and unrecognised by participant of a social action (Cotgrove 1967: 34). He interpreted patterns of social behaviour in terms of their contribution to the functioning of social system so carefully that enabled him to avoid fallacies of other functionalists. This was due to his ability of distinguishing between the manifest and latent function of social system. It had a far-reaching effect on other sociologists, for it established in them an expectation of the possibility of discovering latent function in every system.

However, the theory of Structural Functionalism did not remain immune to criticism, as it had its own share of it, especially, as regards to its earlier forms of formulation. One of the aspects that drew criticism was that of the error of confusing a structural element with its function. It is argued that religious organizations play a substantial role in the integration of society and its tension management. Since, these two roles constitute the essential elements of any social system, they are considered of 
functional necessity to social system. However this argument is deficient as it overlooks the possible functional alternative. For example, pen function is writing. This function can also be performed by a typewriter, hence, provides a functional alternative to pen, the same could be held true in the case of religious organizations as far as their function is concerned (Caplow 1971: 187).

In short, Structural Functionalism as a sociological theory views society as a social system, consisting of functionally related parts whose contributions are essential to the existence of the whole. It holds every structural element of the social system to be tasked with certain manifest functions in relation to the whole. However, it may also have some latent functions which are not recognised or intended. It presents an optimistic view of society where every component of the system is perceived to be contributing to the functioning of the whole. Furthermore, it perceives society in terms of order and consensus; individual members working together harmoniously based on commonly accepted set of rules and law, hence, contributing to the smooth running of the social system.

From the preceding discussion of the theory of Structural Functionalism it became clear that it presents an analysis of social phenomenon in terms of observable patterns of social behaviour and structure. It fails to take into account the unobservable elements of human behaviour which play significant role in human social behaviour. In this sense it application in studying the social reality of Muslim society is not conducive to its appropriate understanding. For, it is not the structure that determines the behaviour of its members but their intended goals and motives in the light of revealed guidance which fall outside the purview of the method of natural science.

\section{Symbolic Interactionism}

Symbolic Interactionism, unlike Structural Functionalism and Conflict Theory, which are dealing with large-scale phenomena, deals with social phenomena on a small scale. It analyses social phenomena from a subjective perspective. In this sense, it represents more of a social psychological perspective than a sociological perspective. Its origin can be traced to the works of three scholars of nineteenth century, Charles H. Cooley (1864-1929) George Herbert Mead (1863-1931) and William Issac Thomas (1863-1947) scholars at the university of Chicago. Their works are considered to have provided the main sources of Symbolic Interactionism. Thomas, Cooley and Mead were extremely interested to know how an individual acquires personal and social characteristics, in particular, self-identity. They concluded that people were not born with the sense of self. They acquire it through interaction that takes place between them in society (Bryjak \&Soroka1992: 24). Thus, in this sense self-identity can be considered as a social product and not as an instinctive phenomenon, an individual possesses.

In addition, Mead went further and considered human mind itself as a social product of the same social interaction as was the language, the means of thinking. William Issac Thomas, as one of the trio founding fathers of Symbolic Interactionism after undertaking a large-scale study developed strong conviction in ultimate subjective nature of human behaviour. He argued, people respond to an objective event after identifying the situation, personal interpretation of the situation. Their response comes in terms of this subjective reading, regardless of whether it is valid or not. The contribution made by these three scholars formed the foundation of modern theory of Symbolic Interactionism. 
Accordingly, Symbolic Interactionism views social patterns in terms of people's subjective understanding of their social world. It does not see them in terms of examining society's objective properties. For example, a person who is dying of cancer but is not aware of this may act carefree as if he has all the time to live. While, someone who is healthy but is convinced of having developed a terminal illness, may begin to give away his possession even close his affair, even though he has all the time to live in the world. In both cases, knowledge of the objective health of a person terminally ill or healthy is not sufficient in explaining their behaviours. Thus, In order to make a sense out of his/her behaviour it is important to know what he/she thinks of his/her state of health (Bryjak\&Soroka 1994: 25).From the examples given, it becomes clear that a correct understanding of an individual's behaviour is possible when it is explained in the light of its surrounding circumstance and situation. Explaining one's behaviours in terms of its objective value is futile, for it fails to provide an appropriate understanding of why one behaves in a certain way. Symbolic Interactionism analyses social relations on micro-level, as it focuses on millions of small social interactions that constitute the building blocks of large-scale units. It attempts to understand the process through which participants structure these interactions in a harmonious way, without great friction or conflict. As part of these attempts, Symbolic Interactionism examines the role of human communication in construction of subjective meanings that shape people's responses to their world.

Symbolic Interactionism considers communication as a unique phenomenon of human world. In human communication, significant symbols or stimuli, that have meaning and attached values, are used. These meanings and values come into existence as a result of social interaction and people's responses to objects in terms of their symbolic context and not in terms of their physical property. It emphasises on explaining social patterns in their symbolic context, which is subject to negotiation. It sees societies as unfinished structures and continuing process that depend on the subjective perception and interpretation of their members. However, these subjective readings cannot simply constitute a permanent response to the objective condition in the external world.In fact, a focus on the continuous creation of society and its consideration as an ongoing interaction, communication and cooperation, is one of the distinguishing features of Symbolic Interactionism. It also holds consensus in society to emerge as a result of negotiation of the social patterns hence, of no permanent nature. It deals with interaction in general without differentiating between the smallest groups and largest ones (Charo 1991: 147). It interprets society or organization or social patterns in a sense of ongoing interaction, a process of giving and taking, people acting, talking, walking together, influencing each other, buying, selling and so on. These all elements of social action are the focus of the Symbolic Interactionism and not the already established social patterns influencing, controlling and forming human social behaviours.

Symbolic Interactionism also sees society as a cooperation, human being acting together cooperatively with a common commitment to solve their problems and exchange services. It is through this spirit of cooperation that the inherent conflict in all societies is tackled and interaction is made into a society. When they act together to solve the problems they become a society. As people interact with each other they share a perspective, an ordered view of one's world, which functions as a guide to his action. This shared perspective is defined or redefined during their communication and interaction with each other. Besides, shared perspective people develop a shared body of rules, with inner commitment facilitated by interaction called as generalised other which control and guide individuals in their relation towards each other. The resultant shared perspective and 
generalised other out of the process of interaction, constitutes part of what is called culture. Hence, the basic ideas of Symbolic Interactionism can be summarised as follow:

1. People respond to things in a subjective way, they respond to things based on what they mean for them.

2. Meanings and the values assigned to things have no intrinsic values. They are social products that exist due to social interaction.

3. These meanings are of no permanent character hence, their implication may differ depending on their use by individual and the circumstances of their use(Collin 1985: $282,299)$.

When Symbolic Interactionism is considered from the extreme sense of denying the existence of objective social reality, it cannot be integrated to both Structural Functionalism and Conflict Theory. But in a more moderate stand point of view it complements them, by providing a means of understanding the linkage between the external social realities and the varying human social behaviours.

In short, Symbolic Interactionism conceives society as many ongoing instances of interaction, communication and cooperation that culminate in the development of a culture and generalised other; society. Unlike Structure Functionalism, which analyses society on macro-level from an objective perspective, as mentioned earlier, Symbolic Interactionism analyses society on micro-level from a subjective perspective. In addition, like Structure Functionalism and Conflict Theory, it provides a different and productive view of society. Although it denies the existence of objective social reality, it still can be useful to Structural Functionalism and Conflict Theory, by providing them with a means of understanding the linkage between the external social realities and the varying human behaviours.

\section{Conflict Theory}

In contrast to Structure Functionalism, which sees society as a harmonious well-integrated social system, with shared values and common gaols, Conflict Theory presents a different picture of society. It depicts society as an arena of wide spread conflict and struggle at every level of it. Instead of values consensus, as a means of keeping society together, it considers exercise of power to play the role. Institutions, organizations and individuals possessing power are seen as imposing their values and standard of conduct on those without power by use of force and exercise of their power (Bryjak \& Soroka 1994: 21). They develop certain social patterns in a manner that favour their interest and allow them acquisition of more and more power and wealth through the exploitation of the less privileged groups in the society. Thus, Conflict Theory sees society to be structured on the patterns that retain the discriminatory status quo. It favours some and side-lines other by depriving them from their rights through keeping them in their place and not allowing any change that may work in the favour of poor section of the society (Joel 1991).

Moreover, Conflict Theory sees the dissension and sometime open combat as much part of social life as breathing is as part of man physical existence. For example, dissension and conflict exist at every level of society, labour and management, between students and faculty administration, between gangs and community. Even the institution of the family is not spared from it, as is indicated by high rate of divorce. These all are indicators of wide spread conflict that encompass all level of society. This implies that conflict persist 
throughout the existence of society in its all levels. In other words, to be alive is to struggle and fight. Considering Conflict Theory from the sense mentioned above, it presents a pessimistic perspective of society, for it sees society in terms of strife and disorder and turns blind eyes to the harmonious, integrated aspect of social life. Functionalists criticised Conflict Theory for its pessimistic perspective. Therefore, neither Structure Functionalism nor Conflict Theory can lay exclusive right to comprehensiveness and applicability (Bryjak \& Soroka 1994: 22). Certainly, explaining a social phenomenon in terms of either conflict or stability in isolation from each other cannot present a complete picture of social reality. It must be explained in both senses of stability and conflict so as to have a clear and complete picture of the social reality.

Conflict Theory by viewing society as an arena of wide spread conflict, naturally, negates the existence of cooperation in society on voluntary basis. This is due to its assumption of non-workability of the system for all. It view the system to work for those who are wealthy and serves their interest. Despite this, people are forced to cooperate due to their concern for survival or due to their persuasion by powerful in making them believe that it serves their best interest. It views the government as an institution that work for those who are in position of power in the system rather than the system itself (Charon 1991: 141). In other words, all existing institutions, from the viewpoint of Conflict Theory, are functioning in a way that serves only the interests of the powerful and rich but not that of the powerless and poor.

In addition, Conflict Theory perceives consensus as a means of exploitation created and spread by powerful people in the society to enhance their own interest. People believe, in consensus as a unifying factor in society because they are subjected to coercion and manipulation by powerful. Law, moral, values, truth and other patterns of society, despite their common acceptance, are seen in the same light. They do not work for the interest of the common people and serve the interest of the powerful. Hence, considering all these, Conflict Theory sees change as an inevitable need for society in order to remove the existing inequalities. Dehrendorf pinpoints the inevitability of such change saying; "Every society is subject at every moment to change ... and every society experiences at every moment a social conflict" (Ralf 1958: 170). Accordingly, Conflict Theory sees an end to the existing social conflict through revolution which can bring wide spread change and transform society with class struggle to that of without it. Hence, revolution is seen as the only effective means of such a large-scale change in society (Charon 1991: 141).

Despite its diverse origin, Conflict Theory is seen mostly indebted to Karl Marx (1848-1923), due to which some refer to it as Marxism. However, such an attribution may cause some confusion as regards to tracing the origin of the theory. Because the credit of articulating Conflict Theory does not exclusively go to Marx, for others also played an important role in its formulation. Therefore, it is imperative to note that though all Marxists are Conflict Theorists, but not all Conflict Theorists are Marxists. Marx as a Conflict Theorist believed in various stages of the progress of society. According to him, it is people's relation to the means of production that mainly provided the driving force of the progress of society throughout its history. Some individuals in society own the means of production; things used for creation of material objects and wealth and other have only labour to offer in exchange for wages. Things such as land, machines, buildings and technological know-how are the means of production in industrial society. Capitalists use them in order to enhance their private fortunes, the factor that lead to conflict in society (Bryjak\& Soroka 1994:22). 
Marx classified capitalist society basically into two groups; bourgeoisie, those in possession of the means of production and proletariat, those who work for them. Capitalist society consists mainly of these two groups, which according to him were the centre of the conflict in society. The cause of the conflict between them lay in the systematic exploitation of proletariat by bourgeoisie in its quest for wealth and power. This conflict could only end when proletariat group realising their exploitation by bourgeoisie group launch a successful revolution. With the successful launch of revolution, exploitation of the proletariat group will be eliminated and an end will be put to the capitalist system. This will prepare the ground for an economic system, where all people own the means of production and wealth is equally distributed among them, a stage of the history Karl Marx called communism (Charon 1991: 144). However, Marx view of communism is an utopian idea with no evidence of its realization in sight. This can be attributed to his lack of an adequate understanding of human motivation and organization.

Consequently, Marx sees the enhancement of private property as the chief concern of capitalist system. The spirit of competition and self-interest overrides the sense of cooperation and altruism in society. In this type of society, people are treated as commodities. He argues that by virtue of wealth and property people become powerful and dominate and rule the society. They also acquire power in the government by means of wealth and decide which law to be passed and what law to be enforced. Karl Marx writes: "The state is the form in which the individuals of ruling class assert their common interest" (Marx 1963: 223). The implication of Marx's statement is that state is used by the powerful group as an instrument for enhancement of their own private property through using the law and force to protect their property. The policies that the state adopts are in favour of those who are successful, thus protecting and perpetuating the existing inequalities.

However, according to Marx the dominance of powerful group is not only demonstrated through the state, it is also visible through all of its institutions. For example, religion insists respect to order in society, accepting the law, which protect the rich. Education is conducted in a direction that prepares people for taking their positions in the economic order; media promote and enhance the sale of goods. Even the foreign policy of capitalist society is drawn on the patterns that insure a stable supply of raw material and market. In other words, the prevalent institutions in society are functioning in a way that upholds the economic order which protect those who control it. Marx even holds the dominance of the powerful to extend to the mental production of the society, the way people think. He states; "The class which has the means of production at its disposal has control, at the same time over the means of mental production, the ideas of ruling class are in every age the ruling ideas" (Marx 1963: 78). However, it is significant to bear in mind that not all ideas that people held to be true are created by the dominant class. What is meant here is the relative power of the different ideas, for a particular idea that has gained official recognition can be promulgated and systematically acted upon and forcibly sanctioned as guide to social behaviour. It is in this sense that Marx sees the ideas of ruling class as ruling ideas.

Marx developed conflict theory as a means of explaining the prevailing inequality in society. His objective was to provide a systematic understanding of why there were many poor people in society. Struggle between two classes in the society due to the private ownership, constituted the cornerstone of his theory of conflict. Private ownership of the means of production by the few and their accumulation of more and more wealth led to their control over the direction of society. In his view, it was the very notion of control over 
the means of production and the consequent control over the direction of society that caused conflict in society. He saw the possibility of resolving the conflict in society through transformation of private ownership to common ownership, by establishing an economic system called communism where all equally shares everything.

In sum, Marx in analysing society does not give equal emphasis to all aspects of social life and considers economic survival and the making of livelihood to be the prime concern of the people in society. To him, economic organization was the main factor in determining society's other aspects such as religion, values, moral, law, and ideas (Charon 1991: 144). From his understanding of the economic organization it is clear that economic, in his view, play a key role in determining all structures of the society and the type of social relations.

\section{Non-Marxist Version of Conflict Theory}

As mentioned earlier, not all Conflict Theorists are Marxists. Some other alternative views of Conflict Theory are given by other than Marx. Some of the views given by non-Marxist are discussed as follow.

Max Weber (1868-1920) as a Non Marxist Conflict Theorist provides the most important alternative view of the Conflict Theory. Like Marx, he views society as an arena of competition for power among different groups of people. But unlike Marx, he did not see this competition to be limited to the economic aspect of the society only. He sees the conflict in society from a broader perspective and holds it to be due to political and social aspects too. Competition in economic aspects is mainly represented by class struggle; people trying hard to achieve economic goals, some win and some lose. Those with winning edge become rich and have most advantages over others, in terms of having more opportunities and power, hence, directing other people's life. Weber extends this struggle to the political and social aspects of group life. Men and woman, Protestants Catholics and Jews as well as teachers, doctors and lawyer, try to achieve some advantages in society. Some achieve more power, privilege and prestige than the others. They consolidate their position through establishing customs and laws that protect them. But those failed to do so drop to the bottom of social world and have no power and remain as unprivileged in the society (Charon 1991: 145).

Weber analyses conflict in the political aspect in the same light by holding parties and pressure groups to be striving for power in government. Naturally, not all people will be able to achieve what they want, only those who are more successful gain advantages and try to maintain them. Thus, Weber emphasises on understanding of political, economic and social worlds not only through the concept of conflict but also through using other concepts such as advantages, power, prestige and privileges. By taking into consideration other aspects of the competition among different groups in society, Weber was able to present a broader perspective of the Conflict Theory.

Ralf Dahrendorf is another non-Marxist theorist who presented a different version of Conflict Theory from that of Marx. Unlike Marx, who focused on class and Weber who focused on the status group and pressure groups in explaining conflict in society, he stressed on the formal position of authority, in explaining Conflict Theory. To him, the real conflict, in modern society, was between those holding higher position in any organization and those without it. For example, in a factory, conflict occurs between the owners and workers, in a state between political authority and citizens, in the army between recruited 
personal and officers and so on. He perceived authority as the main cause of conflict and inequality because, those people holding formal position of power tend to consolidate their power and direct the system in a way that serve their interest. Since, those without any formal position of power have different interests; the system does not work on their behalf (Charon 1991: 144). According to him, the conflict arises between those with and without authority due to the manipulation of authority by the former in their own interest at the cost of the latter.

Lewis Coser, is another conflict theorist who made contribution of different sort to the Conflict Theory. In analysing the theory from a different angle, he was able to throw some light on its positive consequences. Unlike other conflict theorists whose treatment of the theory is dominated by negative connotations, he treats it from a positive aspect. He holds that conflict in a group can produce some positive results. For example, in army the threat of enemy is continually held up to the soldiers so as to remind them of the conflict with the enemy. This produces positives results among the recruits, as it binds them together and reinforces their commitment towards each other (Coser 1964: 106).

In Coser's view, the search for an outside enemy or exaggeration of the presumed danger the enemy force may not actually pose, not only maintains a group's structure, it also strengthens it against the danger caused by relaxation of energies or internal dissension. However, conflict in a group can yield positive results only when the parties involved are given a free and fair chance to express their differences openly in an amicable atmosphere with the intention of negotiation. On the other hand, if they are not given the opportunity to express their differences openly through negotiation, such a conflict may produce some negative consequences. For, not allowing them to express their contention amounts to suppressing their feeling which may gradually lead to outburst and cause serious damage to a group specially when it is of small size e.g. family group where emotional feeling are high.

From the preceding discussion of the three major sociological theories namely, Symbolic Interactionism, Structure Functionalism and Conflict theories and its varieties, it become clear that there are certain fundamental factors that influence social phenomenon. An insight to these factorsis conducive to an appropriate and comprehensive explanation of a social reality. They can be considered as the universal elements of the social phenomenon which are elaborated in the following section.

\section{The Universal Elements of Social Phenomenon}

Humans have some primary needs such as food, shelter, sexual satisfaction, protection and so on. The satisfaction of such needs require adaption of some techniques and means for growing or finding and distributing food. It also require the construction of dwelling and the establishment of heterosexual relation. In addition to the primary needs there exist secondary need which is the need for communication and language. In order to enhance cooperation and control conflict social norms and social sanctions are deemed necessary (Malinowski1962:132-33). If we were to analyse these primary and secondary needs in the context of the means of their realization we would be able to conclude that human beings are social beings. They organize themselves into groups, which at certain levels of totality forms society. The motive behind their inclination toward participation with each other and hence, formation of the society, as Mukherjee holds, stems first from their biological obligation and biological privilege. For, in the case of former they are obliged to depend on 
other due to the long period of childhood and also that of old age, whereas, the latter is due to intellectual capabilitythrough which the necessity of coming together and formation of groups and finally society, is realized. Human beings due to their mental capacity can adapt to the nature and exploit it to their benefit. This is possible only through organization and formation of various kinds of groupings and not in isolation. How groups are formed or how many of them are there, is beyond the scope of this article, as it is concerned with intended goals behind the formation of groups and society.

Evidently, humans tendency of organizing themselves into groups and hence to society is dominated by certain objectives which Mukherjee identified broadly as four cardinal values, applicable to all human beings, namely; survival, security, prosperity and progress (Mukherjee 1991). However, this cardinal valuation of humanity according to him is differently interpreted in the context of what is appropriate or inappropriate, desirable or detestable or good or bad for mankind. These are ordinal valuation by mean of which cardinal valuation is translated in the light of how to survive, be secure in life, and obtain material prosperity and to ensure mental progress. Focus on the 'how' aspect of the realization of the cardinal values shows that they are intrinsic to the human nature, thus, not confined by time and space factors.

These cardinal values are interdependent, for human spicy need society in order to survive at the same time his survival is boosted by security in life. Both survival and security in their turn are assured by material prosperity, which is conducive to wholesome life. Finally mental progress is sustained by wholesome life hence, making it possible for human to realize his potentialities to the fullest extent. These cardinal values are of perennial nature to human society, for, they are mentioned in Western and Eastern philosophical treatise. In fact, they have provided the motive power to human history from the very beginning of human life. For example, human beings exploited the natural sources in order to make fire and light, food and clothes and shelter for survival. They also accumulated material goods of different degree of production through the use of animal and human labour for the purpose of survival and well-being. In addition, by exercising their intellectual capacity they were able to make great progress beginning from the Stone Age, producing stone tools and implements and refining them, and production of rock carvings, paintings and art object in stone (Mukherjee 1991: 13).

Consequently, the four aspects of the cardinal valuation of humankind has always been the concern of social philosophers, including even those who view the worldly life as illusion and the other world as real life. In social science two main formulas have been used to realize the cardinal values. First, Consensus, by means of which individuals are consolidated in groups and are able to realize the cardinal values. Second, Contradiction, individuals are consolidated in group by way of resolving the conflict situations in the context of realizing the cardinal values.

However, in the ancient and mediaeval times the 'why' and 'what will be' aspects of the question on the formation of society and its changing, was not important. This is because the world at that time was the aggregate of societies that were unique in themselves, for example India, China, Greece and Rome to name few. Therefore, humanity concern within the confines of each society was mainly related to the cardinal values namely, survival of the species, security in the life spans of individuals, prosperity and progress which was addressed through Philosophy and ethics. The situation changed with the emergence of capitalism as a stage in social development, which eventually ensured a global market in man and materials. So in the wake of the globalization of the capitalism all 
these discrete societies of the world were integrated and global point of view with regard to the cardinal valuation of humankind become relevant. The emergence of capitalism and socialism on the world scene after the World War I necessitated a global perspective. The need for such a global perspective becomes more essential after the World War II and the emergence of the Third World.

The three phenomena of, the emergence of capitalism versus socialism after the major two World Wars and the emergence of the Third World, lead to movements of the people within and across the different territories, establishing political and economic transactions. This provided tremendous opportunity for accumulation of information on different forms of world societies and the stimulus to social sciences advancement. Consequently, the examination of the cardinal values was no more considered as the prerogative of philosophy and ethics. All specializations on humanity and society interacted and viewed social reality as a complex whole.

Currently, social sciences present different valuations for attaining the cardinal human values. This has led to the emergence of many incompatible appraisals of the social reality. The formulation of the social structure and the social processes in variety of ways is indicative of this. However, all variable valuations of the social structure and social processes can be examined systematically, for they refer to the same entity which is human society (Mukherjee 1991:14). However, this require a more precise and comprehensive knowledge on the most efficient inference for the appraisal of social reality. This is possible only when all constituent elements of the social phenomena are taken into account in the process of the analysis of social system. Thus, departmentalization of the social phenomenon hence explaining it in term of its single constituent element cannot facilitate an appropriate analysis of social phenomenon. For example, to explain a social reality of a society in term of economic factor will not present a clear picture of the social situation. Therefore, to get a crystal clear picture of the social reality other factors representing cardinal valuation of the society should also be taken into consideration. For they are interrelated and collectively influence the social behaviours of human being, as such they constitute the main parameters of the structure of the social phenomenon. Henceforth, any attempt at explanation of social phenomenon disregarding these essential elements as a minimum requirement of social system would not facilitate an appropriate appraisal of a social phenomenon.

\section{An Islamic Perspective}

Sociology due to its emphasis on the application of the method of natural science, as become clear from the preceding discussion of the three major sociological theories, failed to present a complete and balanced picture of social reality. This could be attributed to the exclusion of some elements of social phenomenon which remain beyond the ambitof the method of natural sciences. Therefore, its theories due to the elemental mistake in the study of social phenomenon, cannot accurately explain the social reality of the Muslim societies. However, this does not mean a blanket rejection of the sociologicaltheories, as they may shade some light on some aspects of social phenomenon. Nevertheless, it fails to present a complete and balanced picture of social reality due to its focus on the physical aspect of the social phenomenon and a systematic neglect of the metaphysical aspect of social reality under the guise of scientific method. The universal constituent's elements of social phenomenon which Mukherjee referred to as the cardinal values mentioned in the preceding section are composed of elements that cannot be subjected to purely scientific 
method for the purpose of its analysis. Therefore, a method which has the potential of integrating the metaphysical aspect of the social phenomenon in its appraisal is required. This can facilitate formulation of social theory which are sound theoretically and balanced integratingall constituent elements of social phenomenon.This in the terminology of Islamic Law spelled out as the five principle values namely,religion, life, intellect, lineage and property. Islam recognizes the primacy of these values in the structure of society and their essential role and effect on human social behaviour.It incorporated them in its legal structure and prescribed rules for their realization in practical manner.

Consequently, Islam presents a model of society which internal religious dynamics play a significant, and in certain cases, crucial role in determining the political character and socio-religious courses of the Muslim society. Through its moral law it has addressed the concern of humanity for these values by devising two types of measures; positive or protective and negative or preventive. An example of the positive measuresthat intend to addresses the concern of humanity for the value of religion is the creation of conditions that facilitate worship and establishes the other essential pillars of Islam. The concern for the value of life is addressed through the creation of conditions that are necessary for existence of life. The concern for the value of descendent or progeny is catered for by facilitating family relation. The concern for the value of intellect is addressed through the promotion of the means for the growth of the intellect and the concern for the value of property is addressed by creating proper condition for its growth (Al-Shatibi n.d. 9).

Recognition of these values as the essential elements of human society and formulation of relevant rules for their realization is of epistemological importance in the formation of Islamic sociological theory. This is required due to the interrelatedness of institutions, belief and morals of the society and also to avoid the deficiency of the modern sociological theories which aroused due to the use of inadequate methodology in the analysis of social phenomenon. It is therefore, imperative to review the sociological theories in the light of Islamic world view which method of social analyses is based on reason and revelation. A methodology based on both revelation and reason is capable of presenting a complete picture of social reality for it does not suffice, in analysis of social phenomenon, on its physical aspect but take into consideration its metaphysical dimension as well. Thus, inclusion of both physical and metaphysical aspects in the formulation of social theory is the prerequisite for an appropriate understanding of social reality due to their interrelatedness. This will enhance the scope and contents of sociological theories hence, gain them the characteristic of universal application.

Islam, not only recognise these universal values but also requires its adherents to realize and fulfil them with the right motivation and straight forward ways. Niyazee identifies the right motivation as being for the sake of Allah s.w.t. and the straight forward way of their performance justly and righteously (Niyazee 1994: 242).This is to achieve their utilitarian or moral objective without procuring any undesirable unjust and immoral consequences. Islam, as a unique religion of universal characteristic takes into account this cardinal valuation of human beings from not only physical aspect but also from spiritual aspect. Hence, presents a more comprehensive and dynamic, appraisal of social reality. Therefore, its sociological perspective is characterized with dynamism, for it considers all the constituents elements of the social reality in analysis of social phenomenon.

Consequently, in Islamic perception of social reality it is not only the theoretical aspect that counts but also its practicalaspect. For, it use the law of social behavior to enhance human welfare by creating the right conditions for the realization of the cardinal 
values and their growth in terms of priority and need, in a balanced manner. For example, the cardinal value of religion is given priority over that of life, as is clear from the case of jihad where the cardinal value of life is given up in pursuit of the cardinal value of religion due to the importance of religion in human life. However, the realization of the cardinal value of life should not only be considered in terms of priority but also in terms comparative perspective. This means that if realization of the cardinal value of life involve two different social situations, one involving larger and the other smaller number of people, and there is no way of its realization on both levels than preference should be given to social situation that involve a larger number of people. Therefore, priority and the scope of the realization of the cardinal values, is of crucial importance in the framework of sociological theories of Islamic orientation.

As the formation of individual social behavior is the direct outcome of his/her concern for these basic values, Islam provided rules and regulations that enhance and promote these values in a balanced manner. Thus, its rules and regulation, catering for the basic values that constitute human concern at individual as well as societal level are of sociological importance. Therefore, they can be used as the derivative source for formulation of sociological theories that could lead to an adequate and comprehensive understanding of social realities, hence, enabling sociologists to direct their research in a direction that serves humanity. Since, these values represent both physical and spiritual aspects of human society, their embodiment in sociological theory is conducive to explanation of the social phenomenon in a comprehensive manner. The merit of theory of such characteristic is not due to its comprehensibility but also due to its durability, for the elements in terms of which it try to explain the social phenomenon is not limited by time and space factors hence, are of permeant and universal nature.

Accordingly, an Islamic perspective on sociology is not merely concerned with the explanation of social reality in term of the humanity concern for the preservation of religion, life, intellect, property, and descendent, but also aims at promoting them in line with the divine law by establishing a just social order. Therefore, formulation of a theoretical framework based on the concern and promotion of these values is of epistemological significance. It can be used as convenient means for formation of an idealistically integrated society, representing the totality of human life.

The short comings of modern sociological theories are not only due to their exclusion of some constituent elements of social phenomenon but also due to their inappropriate understanding of their significance in the life of non-western society. For example, the concept of religion in western sociological thought does not go beyond that of certain rituals of individual concern and void of any metaphysical or philosophical relevance, hence, deemed replaceable by science. In the same manner, they have treated other elements of the social reality in fragmentation hence, rendering them to be of no broader implications. Islam as a complete way of life provides a broader picture of social reality by taking all its constituents elements into account. Therefore, its sociological perspective is more viable and systematic, for, it analyses social reality, as an integrated whole from various dimensions. Beside its capacity of presenting an appropriate understanding of social reality, it devises rules and regulation that enhance these aspects of human life in a balanced way without creating any contradictory situation.

To conclude, Structural Functionalism presents an optimistic picture of society by viewing society as a system of functionally related parts, whose function, contributes to the function of the system as a whole. Symbolic Interactionism as another major sociological 
theory views society as a dynamic ever-changing process created out of people's interaction with each other. It also presents an optimistic picture of society by depicting it as cooperation among individuals. However, Structural Functionalism analysis society on a macro level whereas the Symbolic Interactionism present an analysis on a micro level with subjective perspective. Conflict Theory as the third major sociological theory presents a pessimistic view of society, by viewing it as an arena of wide spread conflict and struggle at every level of it. Negating the existence of cooperation in society, it views all existing institutions in society as the means only serving the interests of the powerful and richwhereas, the consensus as a means of exploitation. It sees economic organization as the determining factor in other aspects of society, such as religion, values, moral, laws and ideas. It identify private ownership as the main cause of the problem of society which can be solved by its removal.

Although, these theories throw some light on nature and essence of the social phenomenon they fail to provide a comprehensive appraisal of the social phenomenon. This is due to their unbalanced approach in the analysis of the social phenomenon, by not including all the universal elements of the social phenomenon in its explanation. Therefore, they are not conducive to the proper understanding of human social behaviour hence, inadequate for the reorganization of society and its peaceful existence. This necessitates the adoption of an adequate methodology for the study of social phenomenon by means of which a comprehensive appraisal could be made possible. Certainly, the methodology of modern sociology is not adequate for appraisal of such characteristics of social phenomenon specially, as regards to its application to the context of Muslins society. For, the undercurrent of the social behaviour of its member is heavily influenced by their concern for universal values of religion, life, intellect, lineage and property. Thus a multidimensional methodology capable of viewing social phenomenon collectively in terms of all its constituent elements ranging from spiritual, physical, individual social, mental, and metaphysical dimensions is needed. Therefore, an Islamic perspective on sociology cannot remain indifferent to this intrinsic concern of humanity in explaining social reality. It addresses this line of thought through the principleof maslahah which is the embodiment the concern for preservation of religion, life, reason, descendants and property." and the means leading to them (Al-Ghazali1983). Therefore, by virtue of inclusion of universal values Islam provide not only a comprehensive view of social phenomenon but also the material source for the formation of comprehensive sociological theory.

\section{References}

Bryjak, G J. \& Soroka, M. P. 1994. Sociology: Cultural Diversity in Changing World. $2^{\text {nd }}$ ed. London: Allyn and Bacon.

Caplow, T. 1971. Elementary Sociology. London: Prentice-Hall International, Inc.

Charon, J. M. 1991. Sociology: A Conceptual Approach. $3^{\text {rd }}$ Ed. Boston: Allyn and Bacon.

Cohen, P. S. 1968. Modern Social Theory. London: Heinemann Educational Books Ltd.

Collin R. 1985. Three Sociological Traditions; Selected Readings. London: Oxford University Press.

Coser, L. 1964. The Functions of Social Conflict. Glencoe: Free Press.

Cotgrove, S. 1967. The Science of Society, An Introduction to Sociology. London: George Allen and Unwin Ltd. 
Durkheim, E. 1961. Elementary Forms of Religious Life. Bk. 2. Chap. 5 \& 7. Transl. by J.W. Swain Collier. New York: Macmillan.

Durkheim, E. 1984. Division of Labour in Society. Bk. 2. Chap. 2. Transl. by W. D. Hall. New York: Macmillan.

al-Ghazali, AbuHamid Muhammad Ibn Muhammad. 1983. al-Mustasfa' min 'Ilm al-Usul. Vol. 1. Beirut: Dar al-Kutub al-'Ilmiyyah.

Malinowski, B. 1962. Anthropology. In Encyclopaedia Britannica. New York: York University. Malinowski, B. 1944. A Scientific Theory of Culture. Chapel Hill: University of Carolina Press.

Marx, K. 1963. Selected Writing in Sociology and Philosophy. Ed. by T. B. Bottomore. London: C. A. Watts and Co. Ltd.

Mukherjee, R. 1991. Society, Culture, Development. New Delhi: Sage Publication.

Niyazee, Amran Ihsan Khan. 1994. Theories of Islamic Law. Islamabad: Islamic Research.

Parsons, T. 1949. Position and prospects of a systematic theory in sociology. In Essays in Sociological Theory. New York: Free Press

Radcliffe A. R. B. 1965. On the concept of function in social science. In Structure and Function in Primitive Societies. New York: Free Press.

Ralf, D. 1958. Towards a theory of social conflict. Journal of Conflict Resolution. 2: 175.

al-Shatibi Abu Ishaq, Ibrahim Ibn Musa. n.d. Al-Muwafaqat fi Usul al-Shari'ah. Vo. II. Ed. by Abdullah Daraz. Cairo: Maktabah al-Tujariyyah. 